\title{
Alcance de las reformas normativas en derecho sucesoral a raíz de la Carta Constitucional de 1991 según pronunciamientos de la Corte Constitucional*
}

\author{
Scope of the normative reforms in Right Sucesoral following the Charter of 1991 according \\ to pronouncements of the Constitutional Court \\ Alcance das reformas normativas no Direito das Sucessões à raíz da Carta \\ Constitucional de 1991, segundo os pronunciamentos da Corte Constitucional
}

\author{
Ana Bernal Bueno ${ }^{* *}$ \\ Universidad de Santander, Colombia
}

\section{Resumen}

En este artículo se pretende contestar la siguiente pregunta: ¿Cuál ha sido el alcance de las reformas normativas en materia de Derecho sucesoral a partir del año 1991? Tomando como referente los pronunciamientos de la Corte Constitucional relacionados con la materia, para ello se espera describir lo resuelto en los pronunciamientos seleccionados, en aras de proporcionar a los estudiosos del Derecho sucesoral un compendio de la temática.

Palabras clave: Derecho sucesoral, Reformas normativas, Sentencias de constitucionalidad.

\section{Abstract}

This paper focuses on to answer the following question: What has been the scope of the regulatory reforms in the field of law sucesoral from the year 1991? Taking as reference the pronouncements of the Constitutional Court relating to the matter, for this is expected describe what resolved in the pronouncements selected, in the interests of providing the scholars of the right sucesoral a compendium of the theme.

Keywords: Law sucesoral, The regulatory reforms, Judgments of constitutionality.

\section{Resumo}

Neste artigo se pretende responder à seguinte pergunta: Qual foi o alcance das reformas normativas em matéria de Direito das Sucessões a partir do ano de 1991? Tomando como referências os pronunciamentos da Corte Constitucional relacionados com a matéria; para isso espera-se descrever a decisão nos pronunciamentos selecionados, de modo a proporcionar aos estudiosos do Direito das Sucessões um compêndio da temática.

Palavras-chave: Direito das sucessões, Reformas normativas, Sentenças de constitucionalidade.

Cómo referenciar este artículo: Bernal, A. (2016). Alcance de las reformas normativas en derecho sucesoral a raíz de la Carta Constitucional de 1991 según pronunciamientos de la Corte Constitucional. Pensamiento Americano, 9(17), 95-116.

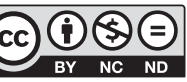

Recibido: Agosto 18 de 2015 • Aceptado: Noviembre 4 de 2015

* Este artículo corresponde al resultado de una investigación titulada: Alcance de la reformas normativas en derecho sucesoral a raíz de la Carta Constitucional de 1991, proyecto adelantado por la suscrita y que se adscribe a la línea de Derecho Privado del Grupo de Investigación Jurisprudencia y Activismo constitucional de la Facultad de Derecho y Ciencias Políticas de la Universidad de Santander-UDES.

** Abogada. Especialista en Docencia Universitaria. Magíster en Hermenéutica Jurídica y Derecho. Docente de tiempo completo de la Universidad de Santander, adscrita al grupo de investigación en Jurisprudencia y activismo constitucional. ana.bernal@udes.edu.co 


\section{Introducción}

Pensar en la sucesión por causa de muerte en la legislación colombiana es hacer un viaje hacia finales del siglo XIX, cuando entra en vigencia el Código Civil Colombiano -año 1873 - y es ubicarse principalmente en el libro tercero de esta codificación, el cual regula la sucesión por causa de muerte y las donaciones entre vivos, en desarrollo de lo contemplado en el artículo 673 de la misma legislación -pero en el libro segundo "De los bienes"- donde se contemplan los modos de adquirir el dominio. $Y$ es viajar a esa época porque pese a los cambios sociales y culturales que se han dado en Colombia desde su entrada en vigencia, lo concerniente a la sucesión por causa de muerte desde el punto de vista del derecho sustancial no ha sido objeto de modificaciones estructurales o significativas por vía legislativa.

Ahora bien, con la entrada en vigencia de la Constitución Política de 1991, al ser la Constitución norma de normas (Artículo 4) y al estar jerárquicamente en un nivel superior a las normas tipo ley, la vigencia de todas las normas preexistentes en el ordenamiento jurídico, quedan supeditadas al respeto de los principios y postulados constitucionales, de tal suerte que por vía de acciones constitucionales de ciudadanos que consideran violatorio del derecho a la igualdad algunas normas del Código Civil, entre ellas las relativas a la igualdad de los hijos, a la igualdad de los cónyuges y compañeros permanentes para reclamar porción conyugal, a los derechos de las parejas del mismo sexo para reclamar derechos herenciales, la Corte Constitucional colombiana se ha pronunciado (Sentencias C-075 de 2007 y C-283 de 2011) ${ }^{1}$ complementando de esta manera normas del libro tercero del Código Civil, por solo citar un ejemplo, se hará alusión a los artículos 1230 a 1238 relativos a la porción conyugal.

Así las cosas, los presupuestos que regulan la sucesión por causa de muerte como modo de adquirir el dominio han sido actualizados en función de defensa de derechos constitucionales, mas no en modificaciones estructurales a lo que ella misma representa, la partición del patrimonio de una persona difunta.

En el mismo sentido, el derecho sucesoral colombiano tiene sus orígenes en la legislación civil española, tanto en lo sustancial como en lo procesal, seguido por el Código Civil chileno de don Andrés Bello, tal como se desprende de lo expuesto por el maestro Pedro Lafont Pianetta -legislaciones todas que bebieron de la influencia del Código Civil de Napoleón de 1804-:

“[...] La legislación precedente al código civil, con pequeñas variaciones que no contemplan la concepción dominante de la forma de legislación hereditaria (generalmente extrajudicial) de la legislación española, siguió aplicándose en nuestro territorio hasta

1 Véanse Sentencias tales como la C-075 de 2007, la C-283 de 2011, entre otras. 
la expedición inicial de los códigos civiles de los estados soberanos y la posterior adopción del Código Civil de Bello, pero en todo el país, el cual (así como aquellos) como lo veremos enseguida, reiteran aquella orientación..." (Lafont, 1993, pp.12-13).

Como se expresó anteriormente, el Código Civil colombiano es adoptado en 1873 -del Código Civil del Gran Santander de 1853, cuando el régimen jurídico se correspondía al de Estados Federados- y desde esa fecha ha conservado la esencia misma de las legislaciones que le dieron origen.

A continuación se mencionan sucintamente las legislaciones que le han modificado, subrogado, derogado, complementado algunos de los artículos del libro tercero (Artículos 1008 a 1442 del Código Civil) ${ }^{2}$ del Código Civil en lo relativo a la sucesión por causa de muerte y que hoy conservan vigencia:

- Ley 57 de 1887, artículo 1021.

- Ley 153 de 1887, artículo 1022.

- Ley 95 de 1890, artículos 1083, 1132.

- Ley 8 de 1922, artículo 1068.

- Ley 45 de 1936, artículos 1242, 1253.

- Decreto 2820 de 1974, artículos 1026, 1330, 1331, 1379.

- Ley 29 de 1982, artículos 1040, 1043, 1045, 1046, 1047, 1048, 1049, 1050, 1051, 1240.

- Decreto 902 de 1988, mediante el cual se

2 Artículos 1008 a 1442 del Código Civil. autoriza el trámite de sucesión por vía notarial.

- Ley 1564 de 2012, mediante la cual se expide el Código General del Proceso y se dic$\tan$ otras disposiciones.

Es decir de un total de 434 artículos, han sido objeto de modificación, subrogación, derogación, complementación un total de 27 artículos que corresponden al $6 \%$.

De esta manera, uno de los modos de adquirir el dominio regulados en el ordenamiento normativo colombiano, es la sucesión por causa de muerte, ello significa que cuando el titular del derecho de dominio fallezca, sus derechos y obligaciones trasmisibles pasarán a ser de sus herederos o legatarios ${ }^{3}$. Esta práctica es en principio la esencia del derecho sucesoral, no embargante, las condiciones particulares del causante, hacen que deba realizarse un especial análisis normativo para definir a la luz del ordenamiento cuáles serán esos derechos, cuáles esas obligaciones y quiénes las personas que darán vida a esa causa sucesoral.

\section{Metodología}

La metodología es cualitativa (jurídica) y el tipo de investigación es teórica de alcance descriptivo ya que se propone evidenciar cuáles han sido las modificaciones introducidas por

3 Los legatarios no representan al causante de tal manera que no se le imponen por ley las obligaciones del causante, su responsabilidad es subsidiaria y se le pueden imponer cargas en la cláusula testamentaria en la cual se le hace la asignación, no obstante, solo se le impondrán las que voluntariamente decida aceptar el legatario. 
la Corte Constitucional en el proferimiento de sentencias con incidencia en el Derecho sucesoral.

\section{Resultados}

En Colombia la mayor parte de la normatividad que contempla el Derecho sucesoral está contenida en el libro tercero del Código Civil, aunque para aplicar lo allí descrito, es necesario complementar con algunos de los institutos jurídicos contemplados en los tres libros restantes. Al igual que con lo regulado en el Código de Procedimiento Civil, hoy Código General del Proceso.

Ahora bien, con la expedición de la Carta Constitucional de 1991, algunos ciudadanos han instaurado acciones constitucionales denunciando la inexequibilidad de varias normas del ordenamiento normativo, con el fin de que la Corte Constitucional en aplicación del artículo 241 y siguientes de la Constitución, interprete las normas demandadas y establezca la conformidad o no conformidad con la Constitución Política, justamente porque el mismo artículo 4 de la Constitución establece que la constitución es norma de normas y no puede haber ninguna norma vigente en el ordenamiento que desconozca lo contemplado en el texto constitucional, así, se han adoptado una serie de decisiones que han incidido en la forma como se interpretan y resuelven los derechos sucesorales, por solo citar unos ejemplos se pueden consultar las sentencias que a continuación se enuncian:

\begin{tabular}{|c|c|}
\hline Año & Número de Sentencia \\
\hline 1994 & $\begin{array}{l}\text { C-105 (Artículo 1016; 1025; 1236; 1242; 1259; } \\
\text { 1261; 1266; } 1277 \text { CC) } \\
\text { C-266 (Artículo } 1022 \text { núm. } 1 ; 1068 \text { núm. 16) }\end{array}$ \\
\hline 1995 & $\begin{array}{l}\text { C-352 (1051 CC) } \\
\text { C-422 (1051 CC) }\end{array}$ \\
\hline 1996 & $\begin{array}{l}\text { C-114 (literal del artículo } 8 \text { de la Ley } 54 \text { de 1990) } \\
\text { C-174 (423, 1016, 1025, 1026, 1040, 1045, 1046, } \\
\text { 1054, 1230, 1231, 1232, 1233,1234, 1235, 1237, } \\
\text { 1238, y del Código Penal Decreto-Ley } 100 \text { de } \\
\text { 1980, el artículo 263 numeral primero) } \\
\text { C-660 (Artículo 1135 del CC) }\end{array}$ \\
\hline 2000 & $\begin{array}{l}\text { C-641 (1226 (parcial), 1241, 1244, 1245, 1250, } \\
1253 \text { (parcial), } 1255 \text { (parcial), 1258, 1261, y } 1274 \\
\text { del Código Civil). } \\
\text { C- } 1264 \text { (el inciso primero del artículo } 125 \text { del } \\
\text { Código Civil. }\end{array}$ \\
\hline 2001 & $\begin{array}{l}\text { C-814 (artículos } 89 \text { y 90, Decreto } 2737 \text { de 1989) } \\
\text { C-1111 (artículo } 1042 \text { CC) }\end{array}$ \\
\hline 2003 & $\begin{array}{l}\text { C-065 (Artículo } 1068 \text { CC) } \\
\text { C-230 (Artículo } 1068 \text { CC) } \\
\text { C-430 (Artículo 1266 CC) } \\
\text { C-901 (Artículo 625 CPC) }\end{array}$ \\
\hline 2004 & C-1029 (Artículo 1068 CC) \\
\hline 2005 & C-101 (Artículo 1134 CC) \\
\hline 2006 & C-398 \\
\hline 2011 & $\begin{array}{l}\text { C-283 (Artículo 1016; 1045; 1054; 1226; 1230; } \\
\text { 1231; 1232; 1234; 1235; 1236; 1237; 1238; 1243; } \\
\text { 1248; 1249; 1251; 1277 CC) } \\
\text { C-577 }\end{array}$ \\
\hline 2012 & C-238 (Artículo 1040; 1046; 1047; 1233 CC) \\
\hline 2013 & $\begin{array}{l}\text { C-513 (Artículo } 1133 \text { CC) } \\
\text { C-529 (Artículo } 1133 \text { CC) }\end{array}$ \\
\hline 2014 & $\begin{array}{l}\text { C-552 (Artículo } 124 \text { CC) } \\
\text { C-683 (Artículo } 487 \text { CGP) }\end{array}$ \\
\hline
\end{tabular}

Fuente: Elaboración propia

Las cuales se han encargado de ajustar y complementar algunas disposiciones del ordenamiento jurídico que se entiende lesionan derechos de las personas que pueden incidir en su derecho a la igualdad, a la no discriminación, al libre desarrollo de la personalidad, a conformar una familia, entre otros. 


\section{Discusión}

Las sentencias que se mencionaron anteriormente han complementado los derechos a la herencia contemplados en los artículos 1008 y siguientes del Código Civil, principalmente frente a la concepción de legitimario, legítimas y derechos para acceder a los bienes de la herencia.

A continuación se presentan las sentencias con los argumentos y decisiones adoptadas por la Corte Constitucional.

En el caso de la Sentencia C-105 de 1994, la Corte Constitucional, considera que la expresión legítimo contenida en los artículos 61; 222; 244; 260; 422; 457; 537; 550; 1016; 1025; $1236 ; 1242 ; 1253 ; 1259 ; 1261 ; 1266 ; 1277$, vulnera el derecho a la igualdad. Pese a lo anterior, se hace necesario mencionar que en materia sucesoral desde la vigencia de la Ley 29 de 1982, todos los hijos, entiéndase matrimoniales, extramatrimoniales, adoptivos, son iguales ante la ley, y por ende tienen el mismo derecho a reclamar los bienes de la herencia, salvo disposiciones testamentarias que mejoren, dentro de los términos de ley a alguno de los hijos o descendientes del causante. La declaratoria de inexequibilidad del término legítimos que en tales normas se equipara a hijo matrimonial, o descendiente matrimonial, abre el campo para todos los hijos y descendientes del causante, independientemente de la condición de hijo matrimonial, extramatrimonial o adoptivo, adaptando la legislación civil a los criterios de no discriminación consagrados en el artículo
13 de la Constitución Política por origen familiar, así como a lo dispuesto en el artículo 42 de la Constitución Política que reconoce la familia conformada en vínculos contractuales, tanto como la conformada por situaciones de hecho.

Del mismo modo, en el caso de la Sentencia C-266 de 1994 donde el accionante considera que el inciso primero del artículo 1022 y el numeral 16 del artículo 1068 del Código Civil violan el derecho a igualdad en cuanto regulan: la incapacidad herencial y la inhabilidad para ser testigo en testamento solemne, excluyendo solo a la religión católica, no obstante ser el Estado colombiano un Estado Laico.

Así las cosas, la Corte declara la exequibiliad respecto de los artículos demandados por considerar que cumplen con las finalidades para las cuales fueron creadas, esto es, mantener la independencia del testador, quien de manera consciente, autónoma, independiente y libre de vicios del consentimiento otorga el acto testamentario.

Seguidamente se tiene la Sentencia C-352 de $1995^{4}$, en la que la Corte Constitucional resuelve una demanda de constitucionalidad respecto de los artículos 1040 (parcial) y 1051 parcial del Código Civil, en la medida que estos consagran la posibilidad que el hijo del hermano sea heredero, pero no permite que los tíos sean herederos en las causas de los sobrinos.

4 En el mismo sentido la Sentencia C-422 de 1995 de la Corte Constitucional, en la que se decide estarse a lo resuelto en la Sentencia C-352 de 1995 sobre la misma materia. 
Se aclara por parte de la Corte que con la expedición del Código Civil, el contenido inicial del artículo 1049 llamaba a heredar a los colaterales legítimos, mientras que con la reforma de la Ley 153 de 1887, el llamamiento era hasta el décimo grado de consangüinidad. No obstante, en el año de 1935 con la expedición de la Ley 60 se redujo hasta el cuarto grado de consangüinidad y por su parte la Ley 29 de 1982 mantuvo hasta los hijos de los hermanos.

Por otra parte, en la Sentencia C-114 de 1996, la Corte Constitucional se pronunció frente a la demanda de inexequibilidad interpuesta por un ciudadano que consideraba que la expresión "o la muerte de uno o ambos compañeros" consagrada en el artículo $8^{5}$ de la Ley 54 de 1990, vulneraba los artículos 5, 13 y 42 de la Constitución Política.

Dada la perentoriedad del término señalado en la norma, la Corte Constitucional aclara en la citada sentencia, que dicho término es de prescripción y no de caducidad, haciendo referencia a las implicaciones de suspensión de prescripción señaladas en el artículo 2541 en favor de las personas señaladas en el ordinal primero del artículo 2530 del Código Civil. Aclarando la Corte que no hay interrupción de caducidad, señalando que la suspensión de la partición y la suspensión de la prescripción

5 "Las acciones para obtener la disolución y liquidación de la sociedad patrimonial entre compañeros permanentes, prescriben en un año, a partir de la separación física y definitiva de los compañeros, del matrimonio con terceros o de la muerte de uno o ambos compañeros.

Parágrafo. La prescripción de que habla este artículo se interrumpirá con la presentación de la demanda”. "hacen que el término de un año sea suficiente para que los herederos de uno de los compañeros permanentes hagan valer los derechos que les reconoce el inciso primero del artículo 6 de la Ley 54" (Corte Constitucional, C-114 de 1996). En la sentencia, la Corte Constitucional declaró la exequibilidad de todo el artículo 8 de la Ley 54 de 1990.

El argumento central de la Corte Constitucional para el año 1996, es que entre la sociedad conyugal y la sociedad patrimonial existen diferencias de carácter normativo que no son contrarias a la Constitución y que es deber del Congreso de la República disminuir esas diferencias por vía legislativa.

Por otra parte, en la Sentencia C-174 de 1996, la Corte Constitucional estudió la constitucionalidad de los artículos: 423, 1016, 1025, 1026, 1040, 1045, 1046, 1054, 1230, 1231, 1232, 1233, 1234, 1235, 1237, 1238, del Código Civil y del entonces vigente Código Penal, Decreto-Ley 100 de 1980 el artículo 263 numeral primero. Sosteniendo que: "El juez constitucional no puede crear una igualdad entre quienes la propia Constitución consideró diferentes, es decir, entre los cónyuges y los compañeros permanentes" (Corte Constitucional, C-174 de 1996).

Entendía la Corte en el año de 1996 que los derechos y obligaciones recíprocos entre cónyuges eran mayores que los que se imponían a los compañeros permanentes, disponiendo que solo el legislador era el competente para 
asignar vocación hereditaria al compañero permanente supérstite. Finalmente resuelve la Corte en la sentencia señalada que las normas del Código Civil demandadas, no vulneran el texto constitucional.

En la Sentencia C-660 de 1996, la Corte Constitucional se pronunció respecto de la constitucionalidad del artículo $1135^{6}$ del Código Civil:

Dados los desarrollos jurisprudenciales con relación al libre desarrollo de la personalidad, a la autonomía personal, a la libertad de conciencia, e incluso frente al derecho a la intimidad, no era muy sencillo decidir si imponer este tipo de condiciones por vía testamentaria estaba o no acorde con el ordenamiento jurídico.

Las primeras reflexiones que hace la Corte Constitucional, son frente al respeto a esa libertad reconocida en el ordenamiento jurídico constitucional, para ello, se plantea si la condición contemplada en el Código Civil es de tipo obligatorio o si es una prohibición, o simplemente se corresponde a una sugerencia, frente a lo cual consideró la Corte en ese momento que la condición: "únicamente determina el estado de cosas que ha de ocurrir para que puedan surgir ciertos efectos jurídicos. Si el asignatario desea que tales efectos se pro-

6 La condición de casarse o no casarse con una persona determinada, y la de abrazar un estado o profesión cualquiera, permitida por las leyes, aunque sea incompatible con el estado de matrimonio, valdrán. duzcan, lógicamente tendrá que intentar cumplir la condición estipulada; pero nunca se le impondrá como una obligación" (Corte Constitucional, C-660 de 1996).

De tal manera que se deja a libre escogencia del asignatario condicional la posibilidad de elegir libremente su estado civil o la de optar libremente por una determinada profesión o la de incrementar su patrimonio aceptando la asignación condicional, según su libre volun$\operatorname{tad}^{7}$.

En el mismo sentido, reflexiona la Corte frente a la libertad que tiene el testador a imponer este tipo de condiciones en cláusulas testamentarias, sustentándola en que esa autonomía privada del testador está respaldada por unas garantías constitucionales contempladas en los artículos 13 y 16 de la Carta Política, así como por normas constitucionales que garantizan la autonomía de la voluntad conforme a los artículos 14, 42, 333, ibídem.

En aplicación de lo atrás mencionado frente al caso concreto, consideró la Corte Constitucional que fue el legislador quien autorizó al testador en desarrollo de su derecho a la propiedad y a la autonomía privada de la voluntad a disponer con libertad de las porciones de cuarta de libre disposición y de cuarta

7 En efecto, en el momento en que una persona acepta una asignación testamentaria condicional se autolimita voluntariamente, en ejercicio de su derecho de libertad. Entonces, solo él tendrá que decidir si cumple o no la condición impuesta por el testador para obtener los beneficios económicos que de allí se derivan (Corte Constitucional, C-660 de 1996). 
de mejoras, manteniendo frente a esta última las limitantes contempladas en el artículo 1253 del Código Civil. Finalmente, declaró la Corte Constitucional exequible el artículo 1135 del Código Civil.

Se cuenta así mismo con la Sentencia C-641 de 2000, en la que se pronuncia la Corte respecto de una demanda de inconstitucionalidad en contra de los artículos 1226 (parcial), 1241, 1244, 1245, 1250, 1253 (parcial), 1255 (parcial), 1258, 1261, y 1274 del Código Civil colombiano.

En ella se declara la exequibilidad de las disposiciones demandadas soportadas en los argumentos de la Sentencia C-660 de 1996, salvo la expresión "naturales" contenida en el artículo 1253 del Código Civil, ello en concordancia con lo dispuesto en la Sentencia C-595 de 1996 en la que se declaró la inexequibilidad de los artículos 39 y 48 del Código Civil en lo tocante con el parentesco ilegítimo ${ }^{8}$.

8 "Finalmente, en cuanto se refiere al artículo 1253 del Código Civil, subrogado por la Ley 45 de 1936, artículo 24, estima esta Corporación que dicha disposición se ajusta al ordenamiento jurídico superior, salvo la expresión "naturales", del inciso primero de dicha norma, la cual se declarará inexequible por cuanto conforme con la jurisprudencia de esta Corporación, especialmente la Sentencia C-595 de noviembre 6 de 1996, M.P. Jorge Arango Mejía, que declaró inexequibles los artículos 39 y 48 del Código Civil, que regulaba el denominado parentesco ilegítimo, consagra la igualdad de trato y de derechos entre los hijos legítimos, extramatrimoniales y adoptivos, establecida por el artículo $1^{\circ}$ de la Ley 29 de 1982, disposición que fue elevada posteriormente a norma constitucional por el inciso $6^{\circ}$ del artículo 42 de la Constitución. Siendo esto así, el calificativo de ilegítimo dado a un parentesco no tiene ninguna finalidad dentro del orden jurídico dispuesto por la Carta Política de 1991, caracterizado por esa jurisprudencia que reconoce, en pie de igualdad, la familia constituida por "vínculos naturales o jurídicos" (artículo 42, inciso $1^{\circ}$ de la C.P.). Luego no se ve cómo la inexistencia del matrimonio origine una "consan-
Seguidamente está la Sentencia C-1264 de 2000, en la que la Corte Constitucional se pronuncia respecto de la constitucionalidad del inciso primero del artículo $125^{9}$ del Código Civil.

Para decidir la petición del accionante, la Corte se cuestiona frente al concepto de contrato de donación entre vivos ${ }^{10}$, y a partir de allí, sostiene que la facultad de revocar mencionada en la norma, está supeditada a la aceptación por parte del Juez de conocimiento, ello de conformidad con lo dispuesto en el artículo 1487 del Código Civil.

Dados los anteriores argumentos encontró la Corte que lo dispuesto en la norma demandada, no limita la capacidad jurídica del menor, ni la validez del matrimonio, ni afecta el estado civil del mismo, por ende, sostuvo en su momento que tal norma no era contraria a lo dispuesto en el artículo 14 de la Carta Política. Con base en tales razonamientos, la Corte Constitucional declaró "exequible el inciso primero del artículo 125 del Código Civil en relación con los cargos formulados" (Corte Constitucional, C-1264 de 2000).

guinidad ilegítima”, entendiéndose esta como ilícita. Así las cosas, en la parte resolutiva de esta sentencia se retirará del mundo jurídico la palabra "naturales", del inciso primero del artículo 1253 subrogado por el artículo 24 de la Ley 45 de 1936" (Corte Constitucional, C-641 de 2000).

9 El ascendiente, sin cuyo necesario consentimiento se hubiere casado el descendiente, podrá revocar por esta causa las donaciones que antes del matrimonio le haya hecho.

10 Contemplado en el Código Civil en los artículos 1143, 1194, 1199, 1200; en contraposición con lo dispuesto en los artículos 1469 y 1470 ibídem. 
En la Sentencia C-814 de 2001, la Corte Constitucional se pronuncia acerca de la constitucionalidad de los artículos $89^{11}$ y $90^{12}$ (parciales) del Decreto-Ley 2737 de 1989, "Código del Menor", vigente para ese entonces.

El accionante consideraba que exigir al adoptante "idoneidad moral" conforme a la redacción de la primera norma demandada, no era acorde con un Estado pluralista y liberal, así mismo, señalaba el accionante que tal exigencia era una carga adicional que se imponía a quienes desearan acoger esta figura jurídica para ser padres.

Así mismo, la demanda parcial en contra del artículo 90 del Código del Menor se dio con relación a la exigencia de estar conformada la pareja adoptante por un hombre y una mujer, excluyendo de tal alternativa jurídica a las uniones homosexuales.

Al hacer los análisis concluye la Corte Constitucional, que prima facie los apartes de

11 Podrá adoptar quien, siendo capaz, haya cumplido 25 años de edad, tenga al menos 15 años más que el adoptable y garantice idoneidad física, mental, moral y social para suministrar hogar adecuado y estable al menor. Estas mismas calidades se exigirán a quienes adopten conjuntamente. El adoptante casado y no separado de cuerpos solo podrá adoptar con el consentimiento de su cónyuge, a menos que este último sea absolutamente incapaz para otorgarlo.

Esta norma no se aplicará en cuanto a la edad, en el caso de adopción por parte del cónyuge conforme a lo previsto en el artículo 91 del presente código.

12 Pueden adoptar conjuntamente:

1. Los cónyuges

2. La pareja formada por el hombre y la mujer que demuestre una convivencia ininterrumpida de por lo menos tres (3)

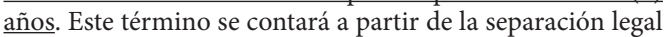
de cuerpos, si con respecto a quienes conforman la pareja o a uno de ellos, estuviere vigente un vínculo matrimonial anterior. las normas demandadas dejan ver que hay desconocimiento de lo regulado en el artículo 13 de la Constitución Política, en lo concerniente a discriminación por razón de sexo. Más, al hacer un análisis de la forma de familia protegida en el artículo 42 en concordancia con la prevalencia del interés superior del menor contemplada en el artículo 44 constitucional, entendiendo que existía una tensión entre los dos derechos mencionados, inclinando la balanza a favor de lo que la Corte entendió en su momento como interés superior del menor. Declarándose finalmente por parte de la Corte Constitucional que los apartes demandados, estaban conformes con lo dispuesto en la Constitución Política.

En la Sentencia C-1111 de 2001, la Corte Constitucional estudió y resolvió una demanda de inconstitucionalidad en contra del artículo $1042^{13}$ del Código Civil. Sostenía el accionante que la norma demandada desconoce el preámbulo y el artículo 13 de la Carta Constitucional, en la medida que trata como diferentes a quienes son iguales. Ello en razón a que hay eventos en los cuales todos los descendientes que hacen presencia en una causa sucesoral lo hacen en su condición de representantes de los hijos que están inmersos en algunas de las causales

13 "Los que suceden por representación heredan en todos casos por estirpes, es decir, que cualquiera que sea el número de los hijos que representan al padre o madre, toman entre todos y por iguales partes la porción que hubiere cabido al padre o madre representado".

"Los que no suceden por representación suceden por cabezas, esto es, toman entre todos y por iguales partes la porción a que la ley los llama, a menos que la misma ley establezca otra división diferente”. 
contempladas en el artículo 1044 del Código Civil. Ante tal eventualidad, esto es, cuando todos los que suceden, lo hacen por derecho de representación, siendo todos nietos del causante, reciben diferente cuota, en aplicación de lo dispuesto en el artículo demandado.

Para resolver la petición, la Corte Constitucional, analiza el instituto jurídico del derecho de representación en su esencia misma, llegando a la conclusión que, la igualdad protegida en tal instituto hace alusión a las estirpes, donde todas las estirpes que hagan presencia en la causa sucesoral reciben por igual, sin importar el número de cabezas de los representantes. En esas condiciones, resuelve la Corte que la norma acusada no vulnera el texto constitucional y declara la exequibilidad del mismo.

En la Sentencia C-065 de 2003, la Corte Constitucional se pronuncia respecto de la constitucionalidad de los numerales 5, 6 y 7 del artículo $1068^{14}$ del Código Civil, por considerar que estos vulneraban los derechos a la igualdad y a la buena fe de las personas en situación de discapacidad física, poniéndolos en situación de desventaja frente a otras personas.

Evidentemente, cuando la norma fue expedida encontraba una finalidad legítima, por cuanto en dicha época no se contaba con el avance científico y tecnológico que le ha per-

14 "Artículo 1068. No podrán ser testigos en un testamento solemne, otorgado en los territorios: (...)

5. Los ciegos;

6 Los sordos;

7. Los mudos; (...)". mitido a quienes padecen ese tipo de limitaciones desarrollar plenamente sus capacidades $y$, por ello, consideró entonces el legislador que dichas personas no podían testimoniar sobre el otorgamiento de un acto solemne como lo es el testamento. ${ }^{15}$

Con base en lo anterior, declara la Corte la inconstitucionalidad de los numerales 5, 6 y 7 del artículo 1068 del Código Civil, por considerarlos contrarios a lo dispuesto en los artículos 13, 47 y 54 de la Constitución Política.

Respecto del numeral 13 del artículo 1068 frente a la inhabilidad para ser testigo el cónyuge del otorgante del testamento, entiende la Corte que sí se ajusta a Derecho, al ser concordantes con lo dispuesto en los artículos 501, 1053, 1056, 2170 del Código Civil y 906 del Código de Comercio, en aras de cumplir con la finalidad de autonomía e independencia en el otorgante del acto testamentario.

En la Sentencia C-230 de 2003, la Corte Constitucional se pronuncia respecto de la constitucionalidad del numeral $8^{16}$ del artículo 1068 del Código Civil, considerando el accionante que la norma acusada viola los artículos 13, 14, 21 y 28 de la Constitución Política. Los

15 Cita la Corte los antecedentes de las sentencias como la C-401 de 1999 en la que se declaró inconstitucional los numerales 5, 6 y 7 del artículo 127 del Código Civil que les prohibía ser testigos para presenciar y autorizar un matrimonio civil.

16 "Artículo 1068. No podrán ser testigos en un testamento solemne, otorgado en los territorios: (...)

8. Los condenados a alguna de las penas designadas en el artículo 315 , número $4^{\circ}$, y en general, los que por sentencia ejecutoriada estuvieren inhabilitados para ser testigos (...)". 
argumentos de la sentencia giran en torno al concepto de inhabilidad para testimoniar, resaltando el interés del legislador en la idoneidad del testigo, máxime frente al acto jurídico unilateral del testamento. Declarándose exequible de manera condicionada la disposición demandada, condicionalidad sujeta al tiempo de duración de la pena privativa de la libertad.

En la Sentencia C-430 de 2003, la Corte Constitucional se pronunció respecto de la constitucionalidad del numeral $5^{17}$ del artículo 1266 del Código Civil. Para resolver el caso, la Corte se centró en cuatro temas específicos: a) la propiedad privada; b) el derecho de sucesiones; c) la autonomía de la voluntad; d) el derecho limitado de testar.

La Corte sustenta que los artículos 15, 16 y 42 de la Constitución Política garantizan la libertad individual, el derecho a la dignidad personal y que las relaciones de familia deben fundarse en la igualdad de derechos y deberes de la pareja y respeto recíproco de todos sus integrantes, dándose prioridad a la libertad personal sobre las particulares consideraciones del testador, favoreciendo la arbitrariedad, de tal manera que declaró la inexequibilidad del numeral 5 del artículo 1266 del Código Civil

17 "Artículo 1266. Un descendiente no puede ser desheredado sino por alguna de las causas siguientes:

(...)

5. Por haber cometido un delito a que se haya aplicado alguna de las penas designadas en el número 4 del artículo 315 , o por haberse abandonado a los vicios o ejercido granjerías infames; a menos que se pruebe que el testador no cuidó la educación del desheredado.

Los ascendientes podrán ser desheredados por cualquiera de las tres primeras causas". y se inhibió para pronunciarse respecto del inciso segundo del numeral 5 del artículo 1266 del Código Civil por ineptitud sustantiva de demanda.

En la Sentencia C-901 de 2003, la Corte Constitucional se pronunció respecto de la demanda de inconstitucionalidad parcial del numeral 2 del artículo $625^{18}$ del Código de Procedimiento Civil ${ }^{19}$. Así las cosas, sostiene la Corte que la interpretación que se hace "en los procesos de liquidación de sociedad conyugal a causa de sentencia religiosa, una vez corrido el traslado de la demanda y cuando esta no se presenta de consuno, a proponer las excepciones previas de: falta de jurisdicción (num. $1^{\circ}$ ), falta de competencia (num. $2^{\circ}$ ), inexistencia del demandante o demandado (num. $4^{\circ}$ ), incapacidad o indebida representación de las partes (num. $5^{\circ}$ ), no haberse presentado prueba de la calidad de cónyuge (num. $6^{\circ}$ ), ineptitud de la demanda (num. $7^{\circ}$ ) y pleito pendiente (num. $10^{\circ}$ ). Ello en la medida que la naturaleza misma de tales excepciones previas es acorde

18 Liquidación a causa de sentencia de jueces eclesiásticos. Cualquiera de los cónyuges podrá pedir la liquidación de la sociedad conyugal disuelta a causa de sentencia eclesiástica, si acompaña copia auténtica de la misma, y el certificado de matrimonio con la constancia de haberse tomado nota de ella.

Para la liquidación se aplicarán las siguientes reglas:

2. El demandado solo podrá proponer las excepciones distintas de las previas contempladas en los numerales $1^{\circ}, 2^{\circ}$,

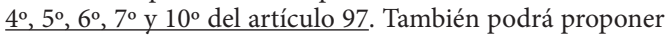
como excepción previa la cosa juzgada, y que el matrimonio no estuvo sujeto al régimen de comunidad de bienes. (...)"

19 "...es en realidad producto de un simple error gramatical en que incurrió el legislador extraordinario de 1989, consistente en haber incluido al momento de la redacción de la norma el adverbio "solo" en vez del advernio no, este último utilizado por la versión original contenida en el Decreto 1400 de 1970 y retomado por la subcomisión redactora del Decreto 2282 de $1989 "$. 
con la naturaleza jurídica de la acción que se interpone.

Finalmente, la Corte Constitucional se inhibe para pronunciarse respecto de la norma demandada por considerar que el accionante no sustentó adecuadamente cuáles eran las violaciones que la norma demandada representaba para la Carta Constitucional, concretamente, se inhibe por ineptitud de demanda.

En relación con la Sentencia C-1029 de 2004, la Corte Constitucional se pronunció respecto de la demanda de inconstitucionalidad del numeral $15^{20}$ del artículo 1068 del Código Civil. Para resolver lo demandado, la Corte reitera los pronunciamientos que ha proferido previamente con ocasión de las demandas a otros numerales del artículo 1068 del Código Civil, reiterando su postura en la medida que lo que se pretende con tales inhabilidades para ser testigo es "proteger la libertad y autonomía de la voluntad del testador, así como la imparcialidad del testigo en el acto a cuyo perfeccionamiento contribuye", declarando finalmente la constitucionalidad del numeral demandado.

En la Sentencia C-101 de 2005, la Corte Constitucional estudió la constitucionalidad del artículo $1134^{21}$ del Código Civil, es de re-

20 Artículo 1068 del Código Civil: "No podrán ser testigos de un testamento solemne, otorgado en los Territorios: (...)

15. Los que tengan con otro de los testigos el parentesco o las relaciones de que se habla en los números 12 y $14 ;(\ldots)$ ".

21 Los artículos precedentes no se oponen a que se provea a la subsistencia de una mujer mientras permanezca soltera o viuda, dejándole por ese tiempo un derecho de usufructo, de uso o de habitación, o una pensión periódica. saltar en el presente caso que la accionante es una defensora delegada para asuntos constitucionales de la Defensoría del Pueblo, por considerar que la norma citada contiene postulados de discriminación negativa en contra de las mujeres, al exigirles mediante cláusula testamentaria condicional el permanecer en soltería o viudez, para acceder a una asignación testamentaria de parte de los bienes de la herencia. ${ }^{22}$

La actora considera que además de vulnerar el derecho a la igualdad, la norma-demandada vulnera el derecho al libre desarrollo de la personalidad consagrado en el artículo 16 de la Carta Constitucional, así como al Derecho a conformar una familia consagrado en los artículos 42 y 43 de la Constitución Política. Así mismo, el artículo $16^{23}$ de la Declaración Universal de Derechos del Hombre, el artículo $17^{24}$ de la Convención Americana sobre Derechos Humanos.

Resolviendo finalmente la Corte Constitucional, con ponencia del magistrado Alfredo

22 Para evidenciar la discriminación a la que históricamente se ha sometido a la mujer, la actora cita referencias bibliográficas como las contenidas en el capítulo V del Emilio de Juan Jacobo Rosseau, lo expuesto por Kierkegaard en el Diario de un seductor, lo dicho por Shopenhauer en Historys of Ideas on woman. Así mismo, cita sentencias de la Corte Constitucional donde se ha pronunciado con respecto a la discriminación negativa a saber: T-098 de 1994, T-624 de 1995, T-326 de 1995, T-026 de 1996, C-309 de 1996, C-410 de 1996, C-622 de 1997, C-082 de 1999, C-112 de 2000.

23 "Los hombres y las mujeres, a partir de la edad núbil, tienen derecho, sin restricción alguna por motivos de raza, nacionalidad o religión, a casarse y fundar una familia, y disfrutarán de iguales derechos en cuanto al matrimonio, durante el matrimonio y en caso de disolución del matrimonio".

24 "Se reconoce el derecho del hombre y la mujer a contraer matrimonio y a fundar una familia si tienen la edad y las condiciones requeridas para ello por las leyes internas, en la medida en que estas no afecten al principio de no discriminación establecido en esta Convención". 
Beltrán Sierra, que la norma citada es INEXEQUIBLE, en tanto vulnera los derechos constitucionales a la igualdad, al libre desarrollo de la personalidad, a conformar libremente una familia. Aclara la Corte que se respetan los derechos que tiene el testador de realizar asignaciones testamentarias condicionales como lo establece el artículo 1128 del Código Civil. Finalmente frente a esta misma sentencia es importante mencionar que hubo un salvamento de voto por parte del magistrado Rodrigo Escobar Gil.

En la Sentencia C-398 de 2006, la Corte Constitucional estudió la constitucionalidad del artículo $41^{25}$ de la Ley 153 de 1887, concretamente frente al conteo de los términos de prescripción regulados por la legislación civil. Se hace necesario aclarar que esta sentencia se analiza en razón a que el artículo 1321 del Código Civil, que regula la acción de petición de herencia, tiene contemplados unos términos de prescripción para hacer efectiva la acción y naturalmente para contabilizar tales términos debe tenerse en cuenta lo dispuesto en el artículo 41 de la Ley 153 de 1887. En el caso concreto consideró el accionante que el aparte del artículo 41 que permite optar por una norma ya derogada y seguir cumpliendo los términos de prescripción o iniciar a contar los términos con la nueva norma que generalmen-

25 Artículo 41. "La prescripción iniciada bajo el imperio de una ley, y que no se hubiere completado aún al tiempo de promulgarse otra que la modifique, podrá ser regida por la primera o la segunda a voluntad del prescribiente, pero eligiéndose la última prescripción no empezará a contarse sino desde la fecha en que la ley nueva hubiere empezado a regir". te los disminuye es contrario a la prevalencia del derecho sustancial sobre el derecho procesal regulada en el artículo 228 de la Constitución Política así como contraria al derecho a la igualdad, consagrado en el artículo 13 ibídem.

Frente a la vulneración al debido proceso sostiene la Corte que la norma demandada es expedida por el legislador disponiendo a partir de cuándo empiezan a contar los términos de prescripción teniendo en cuenta los principios superiores. Finalmente la Corte declara la exequibilidad de la norma demandada.

En la Sentencia C-283 de 2011, la Corte Constitucional estudió la constitucionalidad de los artículos 1016, 1045, 1054, 1226, 1230, $1231,1232,1234,1235,1236,1237,1238,1243$, 1248, 1249, 1251, 1277 del Código Civil. ${ }^{26}$

Arribando la Corte la conclusión que la "porción conyugal" como asignación forzosa es una garantía para la pareja sobreviviente, con independencia de la naturaleza jurídica del vínculo que originó la vida en comunidad. Resolviendo la Corte que las normas demandadas son conformes a la constitución "siempre y cuando se entienda que a la porción conyugal en ellos regulada tienen derecho el compañero o compañera permanente" (Corte Constitucional, C-283 de 2011).

26 El problema jurídico que se planteó la Corte en el presente caso fue: "determinar si resultan contrarios al principio de igualdad, consagrado en los artículos 5, 13 y 42 de la Constitución, las normas del Código Civil que reconocen a favor de los cónyuges sobrevivientes la posibilidad de reclamar la "porción conyugal", facultad que no se reconoce a los compañeros o compañeras permanentes”. 
Finalmente ante el déficit de protección frente a las parejas del mismo sexo, la Corte retoma los postulados de la Sentencia C-075 de 2007 y extiende los derechos a recibir porción conyugal a las parejas del mismo sexo. Así mismo, en el numeral segundo de esta decisión, exhorta nuevamente al Congreso de la República para que legisle de manera sistemática y ordenada frente a las materias relacionadas con las uniones materiales de hecho y frente a las parejas del mismo sexo.

En la Sentencia C-577 de 2011, la Corte Constitucional estudió la constitucionalidad del artículo 113 del Código Civil. En esta ocasión la Corte Constitucional se ocupa de analizar un grupo de demandas que se han instaurado de manera independiente en contra del artículo 113, revisando en cada una de ellos los argumentos que las sustentan y agrupando según puntos de encuentro los argumentos de los accionantes frente a la constitucionalidad o inconstitucionalidad.

Para iniciar el análisis de la conformidad o no de la norma demandada con la Carta Constitucional, la Corte inicia las reflexiones tomando como fundamento el artículo 42 de la Constitución Política, analizando de este: (I) determinar su alcance en relación con la familia y el matrimonio, (II) precisar si da pie a los distintos tipos de familia, (III) establecer si la unión de parejas del mismo sexo responde o no a la noción de familia y, en caso afirmativo, (Iv) dilucidar si es objeto de protección constitucional y (v) en caso de serlo, cuál es el alcance de esa protección y quién está llamado a brindarla" (Corte Constitucional, C-577 de 2011).

La Corte sustenta sus análisis en establecer cuál es el concepto de familia que ha sido aceptado por la doctrina constitucional, citando fallos en los cuales ha sido objeto de análisis esta situación, concluyendo que en la contemporaneidad, en Colombia existen familias conformadas por un hombre y sus hijos, una mujer cabeza de familia y sus hijos, así como por personas que no tienen vínculos de sangre, como ocurre en los eventos en los que es necesario sustituir al grupo familiar de origen por uno que tales funciones, concluyendo la Corte que: "el concepto de familia no puede ser entendido de manera aislada, sino en concordancia con el principio de pluralismo, porque en una sociedad plural, no puede existir un concepto único y excluyente de familia, identificando a esta última únicamente con aquella surgida del vínculo matrimonial".

Un problema jurídico adicional que se analiza en la sentencia y que toca el centro del debate frente a la posibilidad de que el artículo 113 de la Constitución Política facilite la discriminación negativa en contra de las parejas del mismo sexo es el que se plantea a continuación:

\footnotetext{
"Le corresponde a la Corte determinar si, pese a que la unión matrimonial heterosexual y la de parejas homosexuales constituyen tipos de familia, existe un mandato constitucional que imponga aplicar a las pa-
} 
rejas homosexuales, que deseen conformar una familia y solemnizar su unión, la misma forma jurídica prevista para dar lugar a la familia heterosexual surgida de la expresión del consentimiento en que se hace consistir el matrimonio".

Frente a ello la Corte recurre a la concepción de familia que se ha venido desarrollando en el curso de la sentencia y a una interpretación cercana a la literalidad del artículo 42 de la Constitución Política para sostener que la protección constitucional que se hace del matrimonio como vínculo contractual es referente a la pareja conformada por un hombre y una mujer, mientras que la posibilidad de constituir familia se deja abierta en la norma sin que se haga especial alusión a que sea exclusiva de parejas heterosexuales. ${ }^{27}$

En conclusión la Corte resuelve en la sentencia declarar exequible la norma demandada (Artículo 113 del CC) y frente al exhorto al Congreso de la República, la Corte da un plazo perentorio de dos años, para que este legisle acerca del déficit de protección generado por la ausencia de legislación incluyente a favor de las parejas del mismo sexo.

27 "El Constituyente previó la evolución de la institución familiar, pero en el momento mismo de elaborar la Carta no tuvo en cuenta de manera específica opciones como el matrimonio homosexual, puesto que, sin perjuicio de las otras modalidades de familia, se limitó a conferirle una especial expresión en el texto constitucional a una realidad corriente en ese entonces y aún hoy, y de acuerdo con la cual el matrimonio es una de las formas a las que, con mayor asiduidad, acude la gente que desea conformar una familia, forma históricamente ligada a la pareja conformada por un hombre y una mujer, rasgo este que, literalmente, fue incorporado en la Constitución" (Corte Constitucional, Sentencia C-577 de 2011).
Finalmente estableció que pasado el término en silencio, las parejas del mismo sexo “podrán acudir ante notario o juez competente a formalizar y solemnizar su vínculo contractual" (Corte Constitucional, Sentencia C-577 de 2011).

El término fijado por la Corte pasó en silencio legislativo, de tal manera que las parejas del mismo sexo han acudido ante las instancias de Notaría o Juez a solemnizar su vínculo contractual, siendo asumido por estos funcionarios como un contrato de unión solemne con cláusulas y compromisos específicos, bajo la figura del contrato innominado. Los notarios y los jueces no lo han aceptado como contrato matrimonial, dado que este es nominado y la ley ha establecido unos requisitos que dado lo contemplado en la sentencia, las parejas del mismo sexo -ante la ausencia de legislación específica- no reúnen.

En la Sentencia C-238 de 2012, la Corte Constitucional estudió la constitucionalidad de los artículos 1040, 1046, 1047, 1233 del Código Civil. Los cargos del accionante giran en contra de la vulneración del derecho a la igualdad de las parejas tanto heterosexuales, como parejas homosexuales, frente a la expresión "cónyuge" contenida en las normas objeto de demanda. Así, la Corte -en coherencia con las anteriores sentencias promulgadas por esa misma corporación- sostiene que tanto el matrimonio como la unión marital dan origen a familia, existiendo aspectos que las diferencian y aspectos que las hacen similares, debiendo 
analizar si en el caso concreto se deben reconocer las similitudes o si se justifica un trato dispar otorgado por el legislador. ${ }^{28}$

Así, en el caso concreto encuentra la Corte un déficit de protección que carece de justificación objetiva y razonable dado que lo que sustenta el derecho herencial demandado no es el contrato de matrimonio sino la relación familiar, concepto más amplio en el cual se encuentran incorporadas las diferentes formas de familia que se mencionaron en la Sentencia C-577 de 2011.

$\mathrm{Al}$ respecto resuelve la Corte que la vocación hereditaria contemplada en los artículos 1040, 1046, 1047 y 1233 del Código Civil, son exequibles en el entendido que incluyen al cónyuge, al compañero permanente de distinto o del mismo sexo.

En las Sentencias C-513 y 529 de 2013, la Corte Constitucional estudió la constitucionalidad del artículo 1133 del Código Civil.

El problema jurídico que se analiza en la sentencia gira en torno a determinar si existe vulneración del derecho a la igualdad, a conformar una familia y al libre desarrollo de la personalidad, al contemplar en una cláusula

28 Menciona en esta sentencia casos en los que ha reconocido las similitudes con decisiones tales como la C-1033 de 2002, donde autorizó el pago de cuota de alimentos contemplada en el artículo 411 del Código Civil, la Sentencia C-527 de 2007 , relativa a la afiliación al régimen de salud, la Sentencia T-932 de 2008, acerca de la pensión de sobrevivientes, la Sentencia C-096 de 1998 sobre derechos patrimoniales, entre otras. testamentaria la condición de permanecer en estado de viudez para recibir una asignación testamentaria.

Lo primero que hace la Corte es una revisión de sentencias en las que se ha abordado el derecho al libre desarrollo de la personalidad, concluyendo de estas que no le es dable al legislador establecer normas que limiten un derecho tan íntimo de la vida personal del individuo como es la facultad libre y voluntaria de conformar una familia.

Posteriormente analiza el alcance de las disposiciones testamentarias reguladas por la legislación civil, para ello reitera la Corte los postulados de la Sentencia C-660 de 1996 en el análisis de la autonomía privada de la voluntad del testador, ${ }^{29}$ lo cual cambió al resolver la Cor-

29 La ley permite que la voluntad del de cujus se manifieste a través del testamento, es decir, en un acto jurídico unilateral solemne, mediante el cual se determina la forma en que se han de repartir los bienes que se dejan al morir. Recuérdese que la facultad del testador para disponer de sus bienes no es ilimitada pues, para que el testamento sea válido, deben respetarse los órdenes sucesorales establecidos en la ley. De tal forma que, sobre la mitad de los bienes, en el campo de las legítimas, su facultad se limita prácticamente a reiterar lo dispuesto en la ley. Ya en la cuarta de mejoras su competencia se amplía, puesto que puede decidir a cuál, o cuáles de los descendientes les mejorará su asignación, ofreciéndoles una mayor expectativa patrimonial. Por último, es sobre la cuarta parte restante de los bienes, llamada cuarta de libre disposición, sobre la que el testador puede ejercer de manera plena su autonomía de la voluntad.

Ahora bien: teniendo en cuenta que las asignaciones que pertenecen a esta última porción no son forzosas, se explica por qué, como se dijo antes, pueden estar sujetas a condición. La facultad que otorga la ley civil al testador de someter a condición las asignaciones, es un claro reconocimiento de la autonomía de la voluntad, lo que le permite realizar algunos actos que únicamente produzcan efectos en los eventos que él así lo desee. En el caso de este tipo de asignaciones, el testador manifiesta la voluntad de que alguien sea heredero o legatario siempre y cuando se cumpla la condición impuesta. Puede entonces concluirse, que el legislador limita la autonomía de la voluntad del testador, de tal manera que solo le es posible establecer condiciones para la cuarta de mejoras y la de libre disposición. 
te la sentencia en contra del artículo 1134 del Código Civil, lo que se recogió en la Sentencia C-101 de 2005.

Así mismo cita la Corte antecedentes en los que ha declarado inexequible normas del derecho a la seguridad social que condicionaban a que el beneficario no contrajera nuevas nupcias: Sentencias C-309 de 1996, C-182 de 1997 y C-464 de 2004.

Bajo esas premisas, concluye la corte que: el derecho fundamental al libre desarrollo de la personalidad es una prerrogativa constitucional que cuenta con una amplia esfera de protección, la cual cobija de manera especial la facultad que tiene todo ciudadano para decidir sobre la forma en que desea constituir una familia, pues tal elección hace parte del núcleo esencial de tal derecho y no puede ceder en aras de garantizar la facultad del causante para imponer condiciones testamentarias, "pues ese derecho se encuentra sujeto a límites, uno de ellos y de gran significación, el derecho a autodeterminarse en la vida según sus propias convicciones" (Corte Constitucional, Sentencia C-513 de 2013). Finalmente declara la inexequibilidad del artículo 1133 del Código Civil.

Es necesario aclarar que en la Sentencia C-529 de 2013, la Corte se remite a lo resuelto en la Sentencia C-513 de 2013.

En la Sentencia C-552 de 2014, la Corte Constitucional estudió la constitucionalidad del artículo $124^{30}$ del Código Civil. En ella resuelve la Corte dos acciones diferentes contra el mismo artículo, en la que los accionantes consideraron que el artículo demandado vulneraba el derecho a la igualdad (13 CP) al libre desarrollo de la personalidad (16 CP), libertad de conciencia (18 CP), derecho a la familia (42 $\mathrm{CP})$, el derecho a la propiedad (58 CP).

Se plantea el problema jurídico que será resuelto en la presente demanda a saber:
“isi la suplantación de la voluntad del testa- dor por parte de la ley para la imposición de una sanción civil, desconoce los derechos a la autonomía e intimidad familiar del testa- dor $(15 \mathrm{CP})$ y restringe injustificadamente el derecho al libre desarrollo de la persona- lidad del descendiente que al momento de contraer matrimonio requiere autorización por ser menor de edad (16 CP)?" (Corte Constitucional, Sentencia C-552 de 2014).

Ante este problema jurídico debiera plantearse la Corte si tal disposición vulnera la Constitución Política en alguno de los derechos individuales consagrados en la misma, tomando en cuenta adicionalmente cuál es el fin perseguido por la norma demandada,

30 El que no habiendo cumplido la edad, se casare sin el consentimiento de un ascendiente, estando obligado a obtenerlo, podrá ser desheredado no solo por aquel o aquellos cuyo consentimiento le fue necesario, sino por todos los otros ascendientes. Si alguno de estos muriere sin hacer testamento, no tendrá el descendiente más que la mitad de la porción de bienes que le hubiere correspondido en la sucesión del difunto. 
planteándose si esta norma persigue algún fin, constitucionalmente protegido.

De tal manera que en materia sucesoral, el desheredamiento requiere para su validez, el cumplimiento de una serie de requisitos formales, tales como que solo se hace mediante cláusula testamentaria, por alguna de las causales válidas contempladas en la Ley Civil (entre otros requisitos).

No obstante, en el artículo demandado se contempla una excepción a la regla atrás mencionada, frente a la posibilidad de desheredar por vía testamentaria, supliendo tal ausencia de otorgamiento de testamento con una presunción legal de desheredamiento en un $50 \%$ tanto por los ascendientes en quienes recaía la posibilidad de otorgar el permiso para contraer nupcias como por los ascendientes de estos.

Finalmente resuelve la Corte declarar inexequible la expresión "si alguno de estos muriere sin hacer testamento, no tendrá el descendiente más que la mitad de la porción de bienes que le hubiere correpondido en la sucesión del difunto".

En la Sentencia C-683 de 2014, la Corte Constitucional estudió la constitucionalidad del artículo 487 del Código General del Proceso. De la sentencia se extraen varios elementos de interés para esta investigación que se presentan a continuación para mayor ilustración. El accionante presentó cuatro cargos en contra de la norma demandada, no obstante, la Corte
Constitucional colombiana al estudiar la acción los resumió en tres cargos. ${ }^{31}$

No obstante mencionar tres cargos, encontró la Corte que el planteamiento de la demanda no era claro respecto de todos los cargos y resolvió pronunciarse solo frente a los relativos a los vicios por unidad de materia y desconocimiento del derecho a la igualdad, habiéndose planteado dos problemas jurídicos. ${ }^{32} \mathrm{Al}$ revi-

31 (I) Se acusa la violación del principio de unidad de materia (artículo 158) considerando que la figura de la partición en vida es de naturaleza sustancial porque supone la creación de una forma de adquirir el dominio adicional a las establecidas en el artículo 673 del Código Civil, razón por la cual no podía ser regulada por una ley procesal como el Código General del Proceso. (II) Respecto de la figura misma de la partición del patrimonio en vida que introduce el artículo 487 de la Ley 1564 de 2012, se plantea una violación de los artículos 13, 29, 42, 58 y 228 de la Constitución. En este orden de ideas, se considera que el nuevo instrumento perjudica los derechos de los hijos que al momento de la partición no han consolidado su relación paterno filial y de los terceros interesados futuros (ejemplo, acreedores) al privarles de la posibilidad de defender sus derechos en dicho procedimiento (artículo 29), afectando su propiedad privada (artículo 58) -porque el patrimonio que les correspondería es dividido entre los herederos que se reconozcan al momento de la partición- y, por ende, violando el derecho a la igualdad que debe primar entre todos los miembros de la familia (artículos 13, 42). Considerando lo anterior, se argumenta que la figura de la partición en vida se opone al derecho sustancial porque afecta los derechos de ciertos sujetos para favorecer la descongestión jurisdiccional (artículo 229). (III) Con relación a la solicitud de rescisión que la disposición acusada prevé para las personas que acrediten un interés legítimo se alega una violación de los derechos a la igualdad, al debido proceso y al acceso a la administración de justicia de los hijos que al momento de la partición no han consolidado su relación paterno filial y de los terceros interesados futuros. En efecto, el demandante considera que la solicitud de rescisión de la partición es un recurso más complejo, que prescribe en un término más corto con relación a otras acciones similares (artículos 13, 29 y 228) y, adicionalmente, solo se le impone a los hijos que no han nacido o no han sido reconocidos (artículo 13).

32 Los dos problemas jurídicos fueron: 1) ;Se desconoce el principio de unidad de materia (artículo 158) por haberse introducido la figura de la partición de patrimonio en vida, de naturaleza sustancial, en una ley procedimental como el Código General del Proceso? 2) ¿Desconoce la figura de partición de patrimonio en vida los derechos a la igualdad (artículos 14, 42) de los hijos que al momento de la partición no han consolidado su relación paterno filial y de los terceros interesados futuros al no prever la participación de dichos sujetos en pie de igualdad con las demás personas en un proceso que puede afectar su patrimonio? 
sar los problemas jurídicos analizados por la Corte Constitucional colombiana, se considera que estos no tratan el fondo del problema, el cual consiste en que el legislador crea una figura jurídica procesal "reparto de patrimonio en vida" para que le sean aplicables las reglas que regulan la sucesión por causa de muerte, sin que haya coherencia entre la norma creada y los institutos jurídicos propios del Derecho Sucesoral.

Siguiendo con la sentencia de constitucionalidad, la Corte Constitucional colombiana al estudiar los dos cargos atrás relacionados, declara exequible la norma, por considerar que no vulnera los artículos constitucionales mencionados, para lo cual, naturalmente la Corte se limitó a resolver los planteamientos del accionante, sin realizar mayores profundizaciones en los temas que son objeto del problema de investigación que se propone en esta investigación.

\section{Conclusiones}

A partir de la expedición de la carta constitucional de 1991, se ha empezado a hablar de una constitucionalización del Derecho, entendiéndose de una manera sencilla en la forma como los derechos y deberes consagrados en la Carta Política, permean todos y cada uno de los institutos jurídicos existentes; a lo cual el derecho sucesoral no ha sido ajeno y es por ello que en este trabajo se presentan algunos extractos de los argumentos y decisiones adoptadas por la Corte Constitucional cuando se enfrentan la situaciones en las cuales entran en colisión los derechos tipo regla consagrados en el libro tercero del Código Civil y los derechos de rango constitucional.

Una primera conclusión a la que llega el lector será evidenciar en los primeros pronunciamientos la timidez de la Corte frente al reconocimiento de derechos, dándose una mirada a determinados artículos en los años 90 y otra mirada a los mismos artículos en pronunciamiento de los años 2000, principalmente en cuanto a los derechos de las uniones matrimoniales y a las uniones maritales de hecho, siendo la Corte respetuosa de la tridivisión del poder y confiando en la diligencia del legislativo para dar respuesta a las necesidades de una sociedad cambiante que reclamaba atención a sus problemas cotidianos.

Con el paso del tiempo y ante la ausencia de desarrollos legislativos que dieran respuesta encuentra la Corte que los reclamos permanentes de los ciudadanos no tienen eco en el legislativo y empieza a hacer peticiones respetuosas de instar al legislativo para legislar en la materia.

Con posterioridad la Corte en sus sentencias empieza a dar unos plazos para que el legislativo resuelva las lagunas normativas en reconocimiento de derechos y finalmente asume una postura activa señalando qué se debe hacer ante el silencio recurrente del legislativo.

Del mismo modo, se ha podido evidenciar que fue por vía de Sentencias de Constitucio- 
nalidad que se reconocieron derechos a recibir herencia y a recibir porción conyugal a las parejas heterosexuales y homosexuales con unión marital de hecho, siendo claro la intención equiparar sus derechos patrimoniales en materia de derecho sucesoral a los reconocidos tradicional y legalmente a las parejas que cuentan con vínculo de contrato matrimonial.

La imposición de limitaciones a la facultad testamentaria de realizar asignaciones condicionales en las que se exigía abrazar determinada profesión así como el permanecer en estado de viudez (sic), en los pronunciamientos de los años 90 no encuentran vulneración de derechos fundamentales y en los pronunciamientos de los años 2000 fueron objeto de declaratoria de inconstitucionalidad, por ser contrarias a la libre escogencia de una profesión, a la libertad de conciencia, al libre desarrollo de la personalidad, derechos de rango constitucional.

El ajustar los derechos al desheredamiento con los estándares propios del instituto jurídico, esto es, que solo es viable cuando se estipula mediante cláusula testamentaria (en un testamento válidamente otorgado) en la que se establezca que se deshereda con indicación del porcentaje del desheredamiento y se mencione la causal contemplada en los artículos 1266 y siguientes del Código Civil. De tal manera que la sanción legislativa contemplada en el artículo 124 del Código Civil, que pretendía equipararse al instituto jurídico del desheredamiento sale del ordenamiento jurídico.

\section{Referencias}

Calderón, A. (2005). Lecciones de Derecho Hereditario - Sucesión Ab intestato. Segunda edición. Bucaramanga: Editorial UNAB Colección Letra Cátedra.

Corte Constitucional, Sala Plena, Sentencia C-105 de 1994. Expediente D-390, Sentencia 10 de marzo de 1994, M.P. Jorge Arango Mejía.

Corte Constitucional, Sala Plena, Sentencia C-266 de 1994. Expediente D-466, Sentencia 02 de junio de 1994, M.P. José Gregorio Hernández Galindo.

Corte Constitucional, Sala Plena, Sentencia C-352 de 1995. Expediente D-832, Sentencia 09 de agosto de 1995, M.P. Jorge Arango Mejía.

Corte Constitucional, Sala Plena, Sentencia C-422 de 1995. Expediente D-854 y D-855, Sentencia 21 de septiembre de 1995, M.P. Jorge Arango Mejía.

Corte Constitucional, Sala Plena, Sentencia C-114 de 1996. Expediente D-934. Sentencia 21 de marzo de 1996, M.P. Jorge Arango Mejía.

Corte Constitucional, Sala Plena, Sentencia C-174 de 1996. Expediente D-1047. Sentencia 29 de abril de 1996, M.P. Jorge Arango Mejía.

Corte Constitucional, Sala Plena, Sentencia C-660 de 1996. Expediente D-1349. Sentencia 28 de noviembre de 1996, M.P. Carlos Gaviria Díaz.

Corte Constitucional, Sala Plena, Sentencia C-641 de 2000. Expediente D-2684. Sentencia 31 de mayo de 2000, M.P. Fabio Morón Díaz. 
Corte Constitucional, Sala Plena, Sentencia

C-1264 de 2000. Expediente D-2882. Sentencia 20 de septiembre de 2000, M.P. Álvaro Tafur Galvis.

Corte Constitucional, Sala Plena, Sentencia

C-814 de 2001. Expediente D-3378. Sentencia 02 de agosto de 2001, M.P. Marco Gerardo Monroy Cabra.

Corte Constitucional, Sala Plena, Sentencia

C-1111 de 2001. Expediente D-3505. Sentencia 24 de octubre de 2001, M.P. Clara Inés Vargas.

Corte Constitucional, Sala Plena, Sentencia C-065 de 2003. Expediente D-4185. Sentencia 04 de febrero de 2003, M.P. Alfredo Beltrán Sierra.

Corte Constitucional, Sala Plena, Sentencia C-230 de 2003. Expediente D-4297. Sentencia 18 de marzo de 2003, M.P. Alfredo Beltrán Sierra.

Corte Constitucional, Sala Plena, Sentencia C-430 de 2003. Expediente D-4357. Sentencia 27 de mayo de 2003, M.P. Alfredo Beltrán Sierra.

Corte Constitucional, Sala Plena, Sentencia C-901 de 2003. Expediente D-4563. Sentencia 07 de octubre de 2003, M.P. Rodrigo Escobar Gil.

Corte Constitucional, Sala Plena, Sentencia

C-1029 de 2004. Expediente D-5186. Sentencia 21 de octubre de 2004, M.P. Alfredo Beltrán Sierra.

Corte Constitucional, Sala Plena, Sentencia

C-101 de 2005. Expediente D-5342. Sentencia 08 de febrero de 2005, M.P. Alfredo Beltrán Sierra.
Corte Constitucional, Sala Plena, Sentencia C-398 de 2006. Expediente D-6120. Sentencia 24 de mayo de 2006, M.P. Alfredo Beltrán Sierra.

Corte Constitucional, Sala Plena, Sentencia C-283 de 2011. Expediente D-8112. Sentencia 13 de abril de 2011, M.P. Jorge Ignacio Pretelt Chaljub.

Corte Constitucional, Sala Plena, Sentencia C-577 de 2011. Expediente D-8367 D-8376. Sentencia 16 de julio de 2011, M.P. Gabriel Eduardo Mendoza Martelo.

Corte Constitucional, Sala Plena, Sentencia C-238 de 2012. Expediente D-8662. Sentencia 22 de marzo de 2012, M.P. Gabriel Eduardo Mendoza Martelo.

Corte Constitucional, Sala Plena, Sentencia C-513 de 2013. Expediente D-9422. Sentencia 31 de julio de 2013, M.P. Jorge Ignacio Pretelt Chaljub.

Corte Constitucional, Sala Plena, Sentencia C-529 de 2013. Expediente D-9513. Sentencia 14 de agosto de 2013, M.P. Nilson Pinilla Pinilla.

Corte Constitucional, Sala Plena, Sentencia C-552 de 2014. Expediente D-9989 y D-9994. Sentencia 23 de julio de 2014, M.P. Mauricio González Cuervo.

Corte Constitucional, Sala Plena, Sentencia C-683 de 2014. Expediente D-10113. Sentencia 10 de septiembre de 2014, M.P. Mauricio González Cuervo.

Lafont, P. (s.f.). Derechos hereditarios de la filiación extramatrimonial. Bogotá: Ediciones Librería del Profesional. 
Lafont, P. (s.f.). Derecho de Sucesiones. Tomo II. Cuarta edición. Bogotá: Ediciones Librería del Profesional.

Lafont, P. (1982). Igualdad sucesoral. Bogotá: Ediciones Librería del Profesional.

Lafont, P. (1993). Proceso de Sucesión. Parte General. Tomo I. Tercera edición. Bogotá: Ediciones Librería del Profesional.

Lafont, P. (2009). Derecho de Familia - Derecho Marital - Filial - Funcional, Leyes 54 de
1990; 979 de 2005; 721 de 200; 1060 de 2006. Cuarta edición. Bogotá: Ediciones Librería del Profesional.

Naranjo, F. (2009). Derecho Civil Personas y de Familia. 12a edición. Medellín: Librería Jurídica Sánchez R. Ltda.

Parra, J. (2008). Derecho Civil General y de las Personas. Bogotá: Editorial Leyer. 